Original article

\title{
Designing composite external fixator for intertrochanteric fracture treatment based on Vietnamese femur morphological parameters
}

\author{
Quang-Tri Le ${ }^{1}$, Tan-Bao-An Nguyen ${ }^{2}$ \\ ${ }^{1} 7$ A Military Hospital, Ho Chi Minh City, Vietnam \\ ${ }^{2}$ Ho Chi Minh City University of Medicine and Pharmacy, Ho Chi Minh City, Vietnam
}

Received 8 April 2021, Revised 27 May 2021, Accepted 3 June 2021

(C) 2021, Le Q.T., Nguyen T.B.A.

(C) 2021, Russian Open Medical Journal

Abstract: Aim - 60 Vietnamese dry femurs were studied to design a carbon composite external fixator for intertrochanteric fracture. Its mechanical strength was evaluated.

Material and Methods - The femurs were measured by standard goniometers. The fixator injection mold was created by a CNC machine. The fixator material included carbon fiber ( $30-40 \%$ content), BT4, and PA12 plastic. The fixator strength was calculated based on the Finite Element Method.

Results - The average femoral neck-shaft angle, anteversion angle, bowing angle, head diameter, and neck width were respectively $124.85^{\circ}( \pm 7.12), 20.24^{0}( \pm 4.49), 14.90^{\circ}( \pm 3.27), 4.12 \mathrm{~cm}( \pm 0.30)$, and $3.05 \mathrm{~cm}( \pm 0.34)$. A mold and its resulting fixator were designed accordingly. The fixator elasticity modulus, tensile strength, Poisson ratio, and safety factor (K) were $1.32 \times 10^{10} \mathrm{~Pa}, 2.21 \times 10^{8} \mathrm{~Pa}, 0.25$, and 1.5 , respectively, and max load, stress and transposition were 50-150 N, 1.21-1.38 x 10 $\mathrm{Pa}$, and 0.4-1.27 mm, respectively. The composite fixator was more resistant against pressure across the $x$-axis but less against the $y$-axis than the chrome and Inox304 devices. Transposition was the smallest due to its tiny size. Load against $z$-axis pressure was safe for the patients.

Conclusion - This study succeeded to design a prototype carbon composite external fixator with favorable mechanical traits compared with available metal fixators. Further clinical studies are needed to achieve an accurate evaluation of its effectiveness.

Keywords: femur; morphological parameter; carbon composite; external fixator; intertrochanteric fractures.

Cite as Le QT, Nguyen TBA. Designing composite external fixator for intertrochanteric fracture treatment based on Vietnamese femur morphological parameters. Russian Open Medical Journal 2021; 10: e0214.

Correspondence to to Quang-Tri Le. Address: Department of Orthopedic, 7A Military Hospital 466 Nguyen Trai Street, Ward 8, District 5, Ho Chi Minh City 72706, Vietnam. E-mail: latri@ntt.edu.vn.

\section{Introduction}

Intertrochanteric fracture is a common injury in senior patients $[1,2]$. It has a higher occurrence in women and people with osteoporosis [3-5]. Postmenopausal women are especially susceptible to osteoporosis due to estrogen level changes; consequently, women have a much higher intertrochanteric fracture rate than men [6-9]. Recent studies recorded higher intertrochanteric fracture instances: about 50,000 cases annually are recorded in France and 250,000 cases annually in the United States $[10,11]$. An increased number of instances of this injury in senior citizens was also detected, with the rate of patients aged over 80 years augmented from $22.29 \%$ in 1977 to roughly $50 \%$ five years later [12].

Technically, intertrochanteric fracture can be healed relatively quickly due to a good level of blood supply $[1,5]$ with a very low rate of nonunion of femoral head necrosis $(<1 \%)$; however, surgical intervention is required to prevent limb deformity and movement pain. Senior patients also suffer from prolonged bed rest complications, such as pressure ulcers, thromboembolism, or pneumonia, causing high mortality rate. Studies in Vietnam, such as Nguyen Trung Sinh (1984) on 50 patients treated with Whitman casting, recorded poor outcomes for $40 \%$ of cases, including a $26 \%$ mortality rate within the first three months and $14 \%$ incidence of pressure ulcers. Despite the lack of comprehensive statistical data, the intertrochanteric fracture burden on the patients, their families, and society is overwhelming $[8,13]$.

Conservative treatments (casting or unstable methods) may lead to many complications; hence, for intertrochanteric fractures, projected internal stable bone fusion, which causes fewer or less severe complications, guarantees early rehabilitation, and reduces bed rest complications $[14,15]$. Other studies employed external fixators [2, 16-22] to minimize blood loss, anesthetic risks, operation length, early weight-bearing, hospitalization time, and to ensure quick union time; their results showed satisfactory outcomes. External fixators are recommendable, for example, when surgical trauma presents a life threat [23], or for initial treatment of open intertrochanteric fracture, injuries caused by firearms, or for anatomical immobilization of the fracture site; they prevent infection, facilitate injury treatment and prepare proper conditions for further stable bone fusion. 
Prior to 1990, intertrochanteric fractures in Vietnam, despite lack of comprehensive statistics, were probably treated by traditional conservative methods, leading to many complications and a significant mortality rate [13]. From 1990 on, more advanced procedures, using intramedullary rods, dynamic hip screw plates and gamma nails, were introduced [24-28]. However, such treatments were performed mainly at large medical centers for children or senior patients without internal diseases. Fracture treatment is still affected by prolonged surgery, excessive bleeding, significant surgical trauma, the requirement of specialized equipment (such as C-Arm), and risks of nail extrusion in osteoporotic senior patients [26]. Besides, fixation nails, screws and plates in Vietnam are imported rather than manufactured domestically; hence, material supply and compatibility are significant concerns [29].

There are several studies on the implementation of the metal external fixator in Vietnam, such as by Vu Huu Dung [30], Nguyen Van Tin [31], and Le Quang Tri [4]. Recorded data were inadequate for accurate evaluation, but the outcome was encouraging. Moreover, it is possible to manufacture external fixators domestically to solve the supply issues in developing countries with limited financial resources. However, the metal fixator weight and bulkiness necessitated the use of alternative materials, amongst which carbon composites are potential candidates due to low values of their weight, heat resistance, friction and thermal expansion, making them suitable for implementation in Vietnam.

Thus, we conducted our study to design an external fixator using carbon composites suitable for Vietnam. To achieve this goal, we gathered measurement data of the proximal side of Vietnamese femurs and investigated the mechanical strength of the designed external fixator.

\section{Material and Methods}

\section{Research objects}

Bone measurements: we investigated sixty dry specimens of adult Vietnamese femurs (29 right and 31 left femurs). The femurs were randomly chosen (without gender consideration) from the specimens stored at the University of Medicine and Pharmacy at Ho Chi Minh City. The study excluded cracked, broken or defective specimens, or specimens with abnormal and pathological features, such as bone necrosis or bone tumors.

Fixator design and manufacture: crude carbon composite material.

\section{Methods}

Bone measurement. The measurements were performed by the conventional joint goniometer set (Tiger Medical, Inc.) (Figure 1). Nine morphological parameters were recorded (Table 1 ), each was measured three times on the same bone specimen, and the average value was computed.

Statistical methods of analysis. Skewness and kurtosis tests for normality (Sktest) were used to test the normal distribution of the data. The data group with normal distribution was analyzed using a $t$-test and was presented by mean \pm standard deviation. The data group with a non-normal distribution was analyzed using MannWhitney test and was presented by median with lower and upper quartiles.

Data analysis was performed using STATA 10.0 and EXCEL 2007 software.

Mold and carbon composite material. Injection molding was chosen as the method for fixator manufacture. All necessary parts of the fixator were formed in just one mold since their sizes were small. The mold and the fixator were designed based on the parameters measured during the investigation of femur specimens.

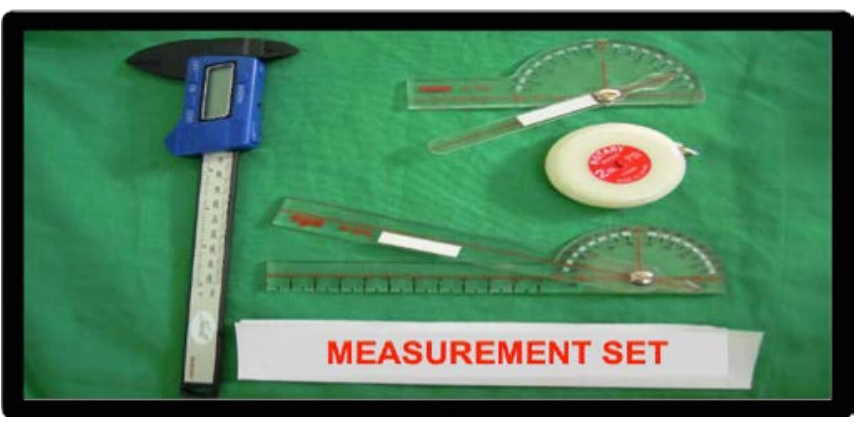

Figure 1. The measurement set for femur specimen investigation



Figure 2. External fixator manufacture process

Table 1. Measured parameters of the femur specimens

Parameters
Neck-shaft angle
Anteversion angle
Femoral bowing angle




\begin{tabular}{|c|c|c|c|c|c|c|c|}
\hline Parameters & & $N$ & Average* & $S E^{*}$ & Min* & Max* & $p$-value \\
\hline \multirow{3}{*}{ Neck-shaft angle } & Left & 29 & 125.79 & 6.35 & 115.00 & 135.00 & \multirow{3}{*}{0.320} \\
\hline & Right & 31 & 123.97 & 7.75 & 103.00 & 138.00 & \\
\hline & Total & 60 & 124.85 & 7.12 & 103.00 & 138.00 & \\
\hline & Left & 29 & 20.51 & 4.49 & 15.00 & 30.00 & \multirow{3}{*}{0.650} \\
\hline \multirow[t]{3}{*}{ Anteversion angle } & Right & 31 & 20.77 & 4.77 & 10.00 & 30.00 & \\
\hline & Total & 60 & 20.24 & 4.24 & 10.00 & 30.00 & \\
\hline & Left & 29 & 14.55 & 3.06 & 10.00 & 20.00 & \multirow{3}{*}{0.650} \\
\hline \multirow[t]{3}{*}{ Bowing angle } & Right & 31 & 15.22 & 3.48 & 10.00 & 30.00 & \\
\hline & Total & 60 & 14.90 & 3.27 & 10.00 & 30.00 & \\
\hline & Left & 29 & 4.07 & 0.28 & 3.50 & 4.60 & \multirow{3}{*}{0.170} \\
\hline \multirow[t]{3}{*}{ Femoral head diameter } & Right & 31 & 4.17 & 0.32 & 3.50 & 4.80 & \\
\hline & Total & 60 & 4.12 & 0.30 & 3.50 & 4.80 & \\
\hline & Left & 29 & 2.96 & 0.32 & 2.20 & 3.60 & \\
\hline \multirow[t]{2}{*}{ Femoral neck width } & Right & 31 & 3.14 & 0.35 & 2.60 & 3.84 & \multirow[t]{2}{*}{0.080} \\
\hline & Total & 60 & 3.05 & 0.34 & 2.20 & 3.84 & \\
\hline \multirow[t]{3}{*}{$A B$} & Right & 31 & 8.30 & 0.52 & 7.40 & 9.80 & \multirow[t]{2}{*}{0.390} \\
\hline & Total & 60 & 8.12 & 0.75 & 6.80 & 9.80 & \\
\hline & Left & 29 & 8.80 & 0.61 & 7.30 & 10.0 & \\
\hline \multirow[t]{3}{*}{$C D$} & Right & 31 & 9.06 & 0.68 & 7.80 & 10.3 & \multirow{2}{*}{0.140} \\
\hline & Total & 60 & 8.90 & 0.65 & 7.30 & 10.3 & \\
\hline & Left & 29 & 8.51 & 0.50 & 7.10 & 9.50 & \\
\hline \multirow[t]{3}{*}{$\mathrm{EF}$} & Right & 31 & 9.03 & 0.53 & 7.90 & 9.90 & \multirow[t]{3}{*}{0.220} \\
\hline & Total & 60 & 8.70 & 0.52 & 7.10 & 9.90 & \\
\hline & Left & 29 & 14.50 & 1.15 & 11.50 & 16.50 & \\
\hline \multirow[t]{2}{*}{ HK } & Right & 31 & 14.89 & 1.29 & 13.00 & 17.00 & \multirow[t]{2}{*}{0.210} \\
\hline & Total & 60 & 14.70 & 1.23 & 11.50 & 17.00 & \\
\hline
\end{tabular}

* - the measurement unit was degree $(0)$ for the angles and $\mathrm{cm}$ for other parameters

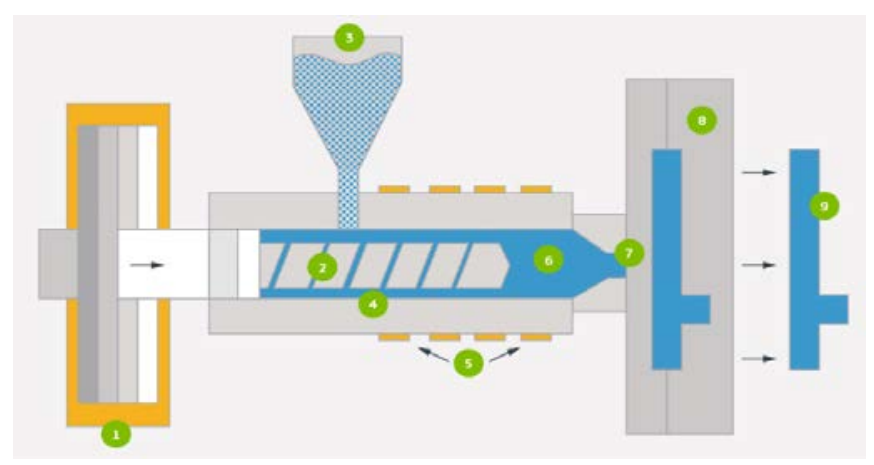

Figure 3. Design of the mold and injection molding machine. (1) Screw motor; (2) Screw; (3) Material hopper; (4) Barrel; (5) Heater bands; (6) Injection chamber; (7) Nozzle; (8) Mold (consists of two halves); (9) Ejected product

The mold was made from CT45 steel, which is resistant to erosion and oxidation, has a high load carrying capacity, melting point and elasticity. The mold consisted of an upper half and a lower half, and comprised automatic ejectors. The mold parts were processed by a CNC machine and were plated.

The composite material was made from a mixture of carbon fiber (HITCO, U.S.), BT4 (NIIGRAFIT, Russia), and polyamide 12 (PA12) plastic pellets, with a $30-40 \%$ fraction of a carbon fiber. The mixture was then processed to make the composite PA12carbon pellets. The material pellets were then forced into the molding machine to form the desirable parts. The operating temperatures were $250-260^{\circ} \mathrm{C}$. The manufacture process is presented in Figure 2.

The designed fixator was investigated for mechanical strength and was compared with available imported fixators. Mechanical strength was calculated based on the Finite Element Method (FEM) $[32,33]$ using the ANSYS ${ }^{\circledR} 13$ software. The testing models were built by specialized CAD software. The structure was modeled three-dimensional, and the solid element was used. The mechanical strength was tested against the pressure across the $x$ axis (i.e., across the fixator main axis), $y$-axis, and $z$-axis (perpendicular to the fixator plane).

Data analysis. The data were processed by STATA 12.0, using appropriate algorithms.

\section{Results} $(\mathrm{N}=60)$

Recorded measurements of Vietnamese femur specimens

The average recorded neck-shaft angle was $124.85^{\circ}( \pm 7.12)$. The corresponding values of anteversion angle, bowing angle, femoral head diameter and femoral neck width were $20.24^{\circ}$ $( \pm 4.24), 14.90^{\circ}( \pm 3.27), 4.12 \mathrm{~cm}( \pm 0.3 \mathrm{~cm})$, and $3.05 \mathrm{~cm}( \pm 0.34 \mathrm{~cm})$, respectively. The corresponding average measurements of $A B, C D$, $\mathrm{EF}$, and $\mathrm{HK}$ were $8.12 \mathrm{~cm}( \pm 0.75 \mathrm{~cm}), 8.90 \mathrm{~cm}( \pm 0.65 \mathrm{~cm}), 8.70 \mathrm{~cm}$ $( \pm 0.52 \mathrm{~cm})$, and $14.70 \mathrm{~cm}( \pm 1.23 \mathrm{~cm})$, respectively. There was no significant difference between the left and right femurs $(p>0.05$, $\alpha=0.95$ ). There was just one specimen with a neck width lower than $2.50 \mathrm{~cm}(1.67 \%)$. The detailed measurements are presented in Table 2.

\section{Mold and external fixator designs}

Injection molding was chosen as the method for fixator manufacture and was described in the Materials and Methods section. The mold design was based on the measurements of the femur specimens and is shown in Figure 3. 


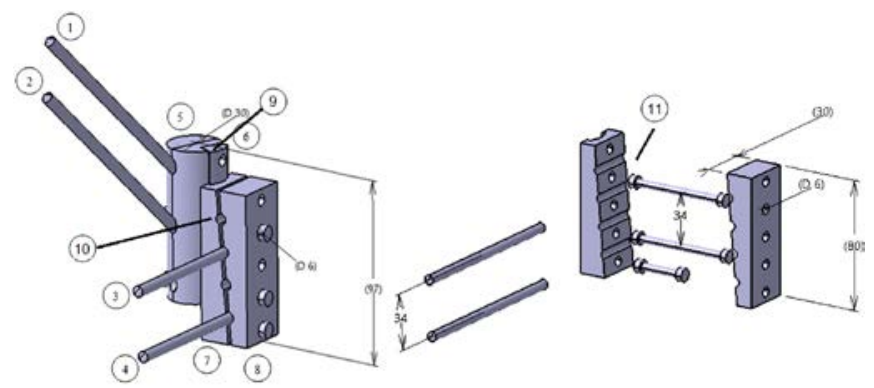

Figure 4. Design of the external fixator. (1) and (2): femoral neck nails, (3) and (4): femoral shaft nails, (5) and (6): anterior and posterior halves of the cylinder, (7) and (8): anterior and posterior halves of the prism, (9): connecting joint between the two parts of the fixator, (10): cross-section separating the prism halves forming a $15^{\circ}$ angle with the coronal plane topdown and back-to-front, (11): halves of fixation rods.

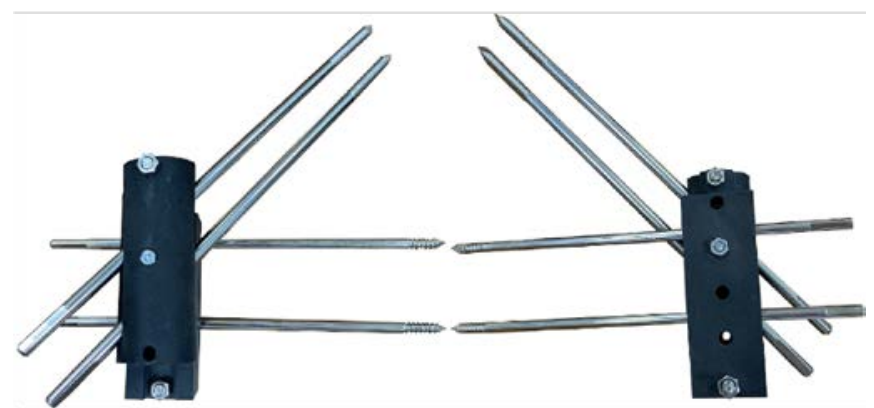

Figure 5. Lateral side and medial side of the external fixator prototype with inserted screws.

The fixator design is presented in Figure 4, and a prototype is shown in Figure 5. The fixator consists of two parts. The bone nails at the proximal femur part were clamped in the ditches between two halves of a cylindrical part used for both left and right limbs. The front half (to the front from the coronal plane) could slide along the ridge to the appropriate ditch of the back half, and the angle between this sliding plane and the screw plane was $20^{\circ}$, similar to the femoral anteversion angle. Two halves of a rectangular prism kept the nails at the femur distal part. The coronal plane angle with the prism halves' contact surface was $15^{\circ}$, similar to the anterior protrusion. fixator

Mechanical strength of the designed composite external

The following composite fixator parameters were measured and recorded: the elasticity modulus, tensile strength, Poisson ratio, and safety factor $(\mathrm{K})$ were $1.32 \times 10^{10} \mathrm{~Pa}, 2.21 \times 10^{8} \mathrm{~Pa}, 0.25$, and 1.5, respectively. Table 3 presents several mechanical strength parameters of investigated fixators vs. other available imported external fixator (for comparison).

\section{Discussion}

\section{Vietnamese femur measurements}

The measurements were performed on 60 randomly selected Vietnamese femur specimens ( 29 of the right femur or $48.33 \%$; and 31 of the left femur bone, or $51.76 \%)$. The measured parameters were not significantly different among the right and left femurs $(p<0.05)$, which was similar to other domestic and foreign studies, such as the research by Nguyen Van Tin [8], or the report by Trinkaus and Anderson (1998) [34]; both asserted an insignificant difference among the legs. The measurements on CT scan images by Baharuddin and colleagues [35] showed an insignificant difference between left and right femurs, but a significant difference between males and females, which could hardly be investigated on dry bone specimen, like those in our study.

The value of the neck-shaft angle is high in infants (on average, $150-160^{\circ}$ ), then it decreases during the body growth, reaching $135^{\circ}$ in adults. This value has been used as a reference for the manufacture of femoral surgical equipment. The neck-shaft angle is a significant parameter for treatment, using a dynamic hip screw or dynamic condylar screw fixators; these surgeries usually require an angle value of $135^{\circ}$ [36]. However, this condition does not seem to fit Vietnamese people, since our study recorded a smaller neckshaft angle ( $124^{\circ}$ for the left side and $126^{\circ}$ for the right side).

Medical publications mention various anteversion angle measurements, including measurements on dry bone specimens; however, it is more convenient to use image materials, such as radiographic, ultrasonic, $\mathrm{CT}$, or $\mathrm{MRI}$ images. The measurements on dry femur specimens were affected, for example, by difficulties in identification of the fovea, or the midpoint on the femoral neck outer surface. The comparison of measurements on dry bones vs. image materials was performed by Aamodt et al. [37]. In our study, the average anteversion angle on dry bones was $20.24 \pm$ 4.240 , within the acceptable range reported in published sources. Another study in India by Rokade and Mane (2009) [38] reported a quite different value $(18.68 \pm 6.37)$. This was probably caused by the difficulties and high subjectivity of these parameter measurements, resulting in a significant difference.

Femoral head diameter and femoral neck width were also important parameters for the suitable design of surgical materials. Our study recorded the value of $4.12 \pm 0.3 \mathrm{~cm}$ and $3.05 \pm 0.34 \mathrm{~cm}$, respectively. The recorded Vietnamese femoral head diameter was quite similar to the parameters of Malaysians but somewhat smaller than those of Europeans and Americans; meanwhile, just a slight difference was found in femoral neck width.

Table 3. Mechanical strength values of carbon composite, chrome, and Inox external fixators

\begin{tabular}{|c|c|c|c|c|}
\hline \multicolumn{2}{|c|}{ Types of external fixators } & \multirow{2}{*}{$\begin{array}{c}\text { Pressure across the } x \text {-axis } \\
50\end{array}$} & \multirow{2}{*}{$\begin{array}{c}\text { Pressure across the } z \text {-axis } \\
150\end{array}$} & \multirow{2}{*}{$\begin{array}{c}\text { Pressure across the } y \text {-axis } \\
90\end{array}$} \\
\hline & Max. load (N) & & & \\
\hline \multirow[t]{3}{*}{ Carbon composite } & Max. stress $(\mathrm{Pa})$ & $1.38 \times 10^{8}$ & $1.21 \times 10^{8}$ & $1.37 \times 10^{8}$ \\
\hline & Max. transposition ( $\mathrm{mm}$ ) & 1.27 & 0.4 & 0.69 \\
\hline & Max. load (N) & 32 & 140 & 120 \\
\hline \multirow[t]{3}{*}{ Chrome } & Max. stress $(\mathrm{Pa})$ & $1.32 \times 10^{8}$ & $1.4 \times 10^{8}$ & $1.37 \times 10^{8}$ \\
\hline & Max. transposition (mm) & 2.3 & 1.76 & 19 \\
\hline & $\operatorname{Max} \cdot \operatorname{load}(\mathrm{N})$ & 50 & 45 & 100 \\
\hline \multirow[t]{2}{*}{ Inox304 } & Max. stress $(\mathrm{Pa})$ & $1.37 \times 10^{8}$ & $1.31 \times 10^{8}$ & $1.4 \times 10^{8}$ \\
\hline & Max. transposition (mm) & 2.49 & 1.25 & 0.55 \\
\hline
\end{tabular}




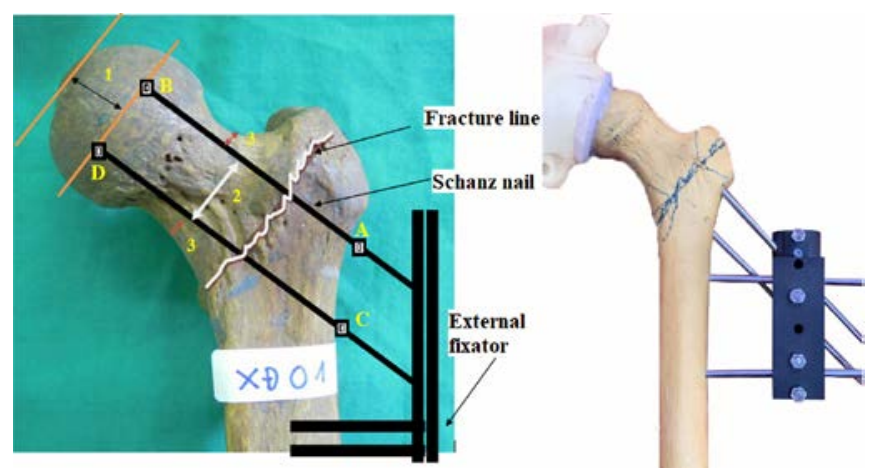

Figure 6 Proposed model for the external fixator and bone nail positions. (1) The Schanz nail tip is $10 \mathrm{~mm}$ from the head cartilage, (2) the distance between two femoral nails is $20-25 \mathrm{~mm}$, and (3) the nails are $2.5-5 \mathrm{~mm}$ from the superior and inferior surfaces of the neck. Hence the length of nails submerged inside the bones should be $A B=80-10=70 \mathrm{~mm}$ and $C D=90-$ $10=80 \mathrm{~mm}$.

Bowing angle is rarely referred to in studies, despite its importance in equipment manufacturing. Our studies recorded a value of $14.90( \pm 3.27)$, which fitted in the range of $10^{\circ}-15^{\circ}$ in Gray's Anatomy.

The lengths of $A B, C D$, and $E F$ are critically important for treating intertrochanteric fracture using external fixator and surgical nails. Our study established $A B=8.12 \pm 0.75 \mathrm{~cm}$, $C D=8.9 \pm 0.65 \mathrm{~cm}, E F=8.7 \pm 0.52 \mathrm{~cm}$, and $H K=14.7 \pm 1.23 \mathrm{~cm} . A B, C D$, and $E F$ measurements fell within the range of $8-9 \mathrm{~cm}$, and were smaller than in other studies, such as by Pires and colleagues (Brazil) [39]. The latter research yielded the value of 8.6-9.4 cm; it was probably due to the fact that the study was based on image materials rather than dry bones.

\section{External fixator design}

The recorded data showed that the mechanical strength against the stress applied across the $z$-axis of the carbon composite fixator was similar to the chrome and Inox304 devices. The mechanical strength against the stress across the $x$-axis, the carbon composite fixator performed better than the other two and yielded a smaller transposition. However, it performed worse against the stress applied across the $y$-axis. The composite fixator was small in size; hence, its bending transposition was smaller than i larger fixators, providing better bone fixation. Its maximum load against $z$-axis pressure was $50 \mathrm{~N}(\sim 5.1 \mathrm{~kg})$, which guaranteed patient safety.

Most of the studies suggested that, for femoral head blood vessel safety, the femoral nails were $10 \mathrm{~mm}$ apart from the femoral head cartilage and 2.5-5 mm apart from the femoral neck superior surface. Our study demonstrated that the average distance between the superior and inferior neck surfaces was 30 $\mathrm{mm}$. With these data, our study proposed a model for nail positioning, presented in Figure 6.

The external fixator design must fit the proximal Vietnamese size of a femur and guarantee stable fixation with a proper union and no malalignment. The femoral nails had to be inserted into the neck and shaft, and attention had to be paid to the factors that contributed to the biomechanics of the intertrochanteric region, including $20^{\circ}$ anteversion angle of the femoral neck, the anterior protrusion of the femur upper third, and the coronal plane of the shaft.

\section{Conclusion}

Based on the measurement of nine morphological parameters of proximal end of the Vietnamese femur, this study succeeded to design a prototype external fixator using carbon composite as material for treating intertrochanteric fracture for Vietnamese patients. Its mechanical strength was comparable to available chrome and Inox external fixators while the transposition was the smallest, which was favorable, and its load against z-axis pressure was safe for the patients. Further clinical studies are required to achieve an accurate evaluation of its treatment effectiveness for intertrochanteric fractures.

\section{Acknowledgements}

We thank our colleagues from the Ministry of Defense, 7A Military Hospital, and the University of Medicine and Pharmacy at Ho Chi Minh City, who provided support and facilities, which were very helpful for our research.

\section{Conflict of interest}

The authors declare that they have no conflict of interest.

\section{References}

1. Guyton JL. Fractures of Hip, Acetabulum and Pelvis. In: Canale ST, Campbell WC, Eds. Campbell's Operative Orthopaedics, 9th ed. St. Louis: Mosby. 1998: 2181-2276.

2. Zayda Al, Zaki EM, Marei S. Ilizarov Fixator in treatment of intertrochanteric fracture femur in geriatric high-risk patients. Biomed J Sci Tech Res. 2018; 2(1): 2325-2358. https://doi.org/10.26717/BJSTR.2018.2.000688.

3. Bejui JB. Ostéosynthése des fractures trochanteriennes. In: Conf ôfenerisd'edseigriemeq4de la SOFOO 46: 1-18. French.

4. Le QT. Treatment of intertrochanteric fractures in senior patients by external fixator under light enhancing monitor. In: Reports in XV annual conference, 2008: 298-309. Vietnamese.

5. Nguyen TS, Nguyen DP, Nguyen XT, Ngu VT. Orthopedics. Hanoi: Medical Publishing House. 2004: 390-394.

6. Ji MX, Yu Q. Primary osteoporosis in postmenopausal women. Chronic Dis Transl Med 2015; 1(1): 9-13. https://doi.org/10.1016/j.cdtm.2015.02.006.

7. Nasab SAM, Khorramdin E. The assessment of mortality and quality of life after intertrochanteric fracture of femur in patients older than 60 at Emam Khomeini Hospital of Ahvaz. Pak J Med Sci 2017; 33(4): 895898. https://doi.org/10.12669/pjms.334.13146.

8. Nguyen VT. Treatment of femoral neck and intertrochanteric fractures by external fixator. HCMC J Med 2003; 292: 151-261. Vietnamese.

9. Tran DT. Osteoporosis in Older People. Hanoi: Medical Publishing House. 1999: 7-55. Vietnamese.

10. Scheerlinck T, Haentjens $P$. Fractures de l'extrémité supérieure du fémur chez l'adulte. In: Encycl Méd Chir (Editions Scientifiques et Médicales), Appareil Locomoteur. Paris: Elsevier SAS. 2003: 14-075-A10. French. http://ekladata.com/gABI 3t4aGxPVj JRmqOsWqbWg/Fractures-de-l-extremite-superieure-du-femur-chez-ladulte.pdf.

11. Lorich DG, Geller DS, Nielson JH. Osteoporotic Pertrochanteric Hip Fractures: Management and Current Controversies. Instr Course Lect. 2004; 53: 441-544. https://pubmed.ncbi.nlm.nih.gov/15116633.

12. Hornby R, Evans JG, Vardon V. Operative or conservative treatment for trochanteric fractures of the femur. A randomised epidemiological trial in elderly patients. J Bone Joint Surg Br 1989; 71(4): 619-623. https://doi.org/10.1302/0301-620x.71b4.2670950. 
13. Nguyen TS. Rehabilitation results of senior intertrochanteric fracture patients. J Surg.1984; 10: 118-121. Vietnamese.

14. LaVelle DG. Fractures of Dislocation of the Hip. In: Campbell WC, Canale ST, Beaty JH, eds. Campbell's Operative Orthopaedics. 11th Ed. Pennsylvania: Mosby/Elsevier. 2008: 3239-3262. https://www.worldcat.org/title/campbells-operativeorthopaedics/oclc/70929249.

15. Capozzi JD, Levy RN, Mont MA. Intertrochanteric Hip Fractures. In: Browner BD, Jupiter JB, Levine AM, Trafton PG, eds. Skeletal Trauma: Fractures, Dislocations, Ligamentous Injuries. 1st ed. Philadelphia: WB Saunders Company. 1992: 1443-1484.

16. Ahmed AR. An innovative external fixator for the management of trochanteric fractures of the femur. Egypt Orthop J 2014; 49(1): 1-5. https://doi.org/10.4103/1110-1148.140522.

17. Vossinakis IC, Badras LS. Management of pertrochanteric fractures in high-risk patients with an external fixation. Int Orthop 2001; 25(4): 219-222. https://doi.org/10.1007/s002640100238.

18. Tomak Y, Kocaoglu M, Piskin A, Yildiz C, Gulman B, Tomak L. Treatment of intertrochanteric fractures in geriatric patients with a modified external fixator. Injury 2005; 36(5): 635-643. https://doi.org/10.1016/j.injury.2004.10.013.

19. Moroni A, Faldini C, Pegreffi F, Hoang-Kim A, Vannini F, Giannini S. Dynamic hip screw compared with external fixation for treatment of osteoporotic pertrochanteric fractures. A prospective, randomized study. J Bone Joint Surg Am 2005; 87(4): 753-759. https://doi.org/10.2106/ibjs.d.01789.

20. Mussa MA, Ahmed AR. External fixation of trochanteric fractures of the femur. J Orthoplastic Surg 2019; 3(1): 74-80. https://journaloforthoplasticsurgery.com/index.php/JOPS/article/view /48ю

21. Vekris MD, Lykissas MG, Manoudis G, Mavrodontidis AN, Papageorgiou CD, Korompilias AV, et al. Proximal screws placement in intertrochanteric fractures treated with external fixation: Comparison of two different techniques. J Orthop Surg Res 2011; 6: 48. https://doi.org/10.1186/1749-799x-6-48.

22. Wang ZP, Liu L, Xue W, Zhou HR, Song YX, Cai LY, et al. Curative effect analysis on closed reduction and external fixator under local anesthesia for the treatment of intertrochanteric fracture in elderly patients with high-risk. Zhongguo Gu Shang 2016; 29(6): 502-504. Chinese. https://pubmed.ncbi.nlm.nih.gov/27534078/.

23. Mitkovic M, Milenkovic S, Radenkovic M, Mladenovic D, Golubovic Z, Stanojlovic M. Surgical treatment of the trochanteric fractures by using the external and internal fixation methods. FU Med Biol 2003; 10(2): 79-83. http://facta.junis.ni.ac.rs/mab/mab200302/mab200302-05.pdf.

24. Mai DD, Le VB, Nguyen TA, Pham Ngoc TA. Preliminary results of intertrochanteric fracture treatment by gamma nails in Thai Nguyen Central General Hospital. J Sci Technol 2014; 118(04): 145-151. Vietnamese.

25. Nguyen HN. Treatment of adult closed intertrochanteric fractures in Viet Duc Hospital - Hanoi. J Surg 2000; 1: 40-43. Vietnamese.

26. Nguyen TB, Nguyen VT, Luu HH, Le HH. Treatment of closed intertrochanteric fractures in senior patients by closed bone fusion using Ender intramedullary rod. Vietnam J Med 2003; Special Issue: 6468. Vietnamese.

27. Pham CL. Intertrochanteric fracture treatment of 70 cases. J HCMC Gen Med 1997; 2(3): 66-70. Vietnamese.

28. Nguyen PN. Intertrochanteric fracture treatment by DHS bone fusion in Ba Ria Hospital. J News Sci Technol Ba Ria Vung Tau 2019; 3: 6-9. Vietnamese.

29. Luong DL. Locking plate for intertrochanteric fracture treatment in senior patient. In: Summary record of the XVI Orthopedics Conference. 2009: 131-136. Vietnamese.

30. Vu HD, Ly TK. Evaluation of intertrochanteric fracture treatment on senior patients using side external fixator. Vietnam J Med 2003; Special Issue: 144-147. Vietnamese.
31. Nguyen VT, Nguyen TB. Treatment of femoral neck and intertrochanteric fractures by external fixator (compressive clockwise and anti-clockwise thread rod). Vietnam J Med 2003; 292: 157-160. Vietnamese.

32. Disegi J. Implant Material: Unalloyed Titanium. 6th Ed. West Chester, PA: Synthes. 2008; 26 p. https://docplayer.net/19907213-Sixthedition-implant-materials-unalloyed-titanium.html.

33. Zienkiewicz OC, Taylor RL. The Finite Element Method for Solid and Structural Mechanics. 7th Ed. Oxford: Butterworth-Heinermann. 2013; 672 p. https://www.elsevier.com/books/the-finite-element-methodfor-solid-and-structural-mechanics/zienkiewicz/978-1-85617-634-7.

34. Anderson JY, Trinkaus E. Patterns of sexual, bilateral and interpopulational variation in human femoral neck-shaft angles. $J$ Anat 1998; 192 (Pt 2)(Pt 2): 279-285. https://doi.org/10.1046/j.14697580.1998.19220279.x.

35. Baharuddin MY, Kadir MRA, Zulkifly AH. Morphology study of the proximal femur in Malay population. Int J Morphol 2011; 29(4): 13211325. https://doi.org/10.4067/S0717-95022011000400042.

36. Pauwels F. Biomechanics of the Locomotor Apparatus. Berlin: SpringerVerlag. 1980; VIII, 520 p. https://doi.org/10.1007/978-3-642-67138-8.

37. Aamodt A, Terjesen T, Eine J, Kvistad KA. Femoral anteversion measured by ultrasound and CT: A comparative study. Skeletal Radiol 1995; 24(2): 105-109. https://doi.org/10.1007/bf00198071.

38. Rokade S, Mane AK. Femoral anteversion: Comparison by two methods. Internet J Biol Anthropol 2009: 3(1): 1-6. https://ispub.com/IJBA/3/1/8728.

39. Pires RE, Prata EF, Gibram AV, Santos LE, Lourenço PR, Belloti JC. Radiographic anatomy of the proximal femur: Correlation with the occurrence of fractures. Acta Ortop Bras 2012; 20(2): 79-83. https://doi.org/10.1590/s1413-78522012000200004.

\section{Authors:}

Quang-Tri Le - MD, PhD, Director, Department of Orthopedics, 7A Military Hospital, Ho Chi Minh City, Vietnam. https://orcid.org/0000-0002-2777$\underline{0828}$

Tan-Bao-An Nguyen - MD, MSc, Lecturer, Department of Plastic and Cosmetic Surgery, Faculty of Medicine, Ho Chi Minh City University of Medicine and Pharmacy, Ho Chi Minh City, Vietnam. https://orcid.org/0000-0002-3090-2262. 